\title{
Combination Therapy with Ruxolitinib and Hydroxyurea for the Treatment of Myeloid-Predominant Leukocytosis in a Patient with Myelofibrosis
}

\author{
Giovanni Caocci $^{a}$ Silvia Ghiani ${ }^{a}$ Cristina Mocci ${ }^{b}$ Giorgio La Nasa ${ }^{a}$ \\ ${ }^{a}$ Hematology Unit, Department of Medical Sciences and Public Health, University of Cagliari, Cagliari, Italy;

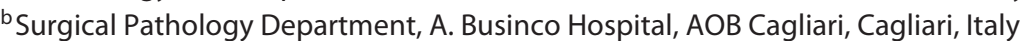

Ruxolitinib is an inhibitor of Janus-activated kinases (JAK1 and JAK2) and approved for the treatment of patients with myelofibrosis (MF) [1]. Despite the wide use of ruxolitinib as first-line treatment since its institutional approval, hydroxyurea (HU) continues to play a role in managing myeloid-predominant leukocytosis in MF. A recent study in a large cohort of MF patients reported that HU was used as first-line treatment in approximately $40 \%$ of patients who presented with a leukocytosis $\left(>25 \times 10^{9} / \mathrm{L}\right)[2]$. Data on the efficacy and safety of the ruxolitinib-HU combination in the treatment of myeloid-predominant leukocytosis in MF are still controversial [3].

In June 2014, a 72-year-old woman was diagnosed with triple-negative overt MF. Physical examination revealed a palpable spleen measuring $7 \mathrm{~cm}$ below the costal margin (Fig. 1). Based on the International Prognostic Scoring System (IPSS), the patient was classified as intermediate- 2 risk [4]. The patient started treatment with ruxolitinib at a dose of $15 \mathrm{mg}$ b.i.d. After 4 weeks, the spleen was no longer palpable below the costal margin, and systemic symptoms resolved. Over the next 18

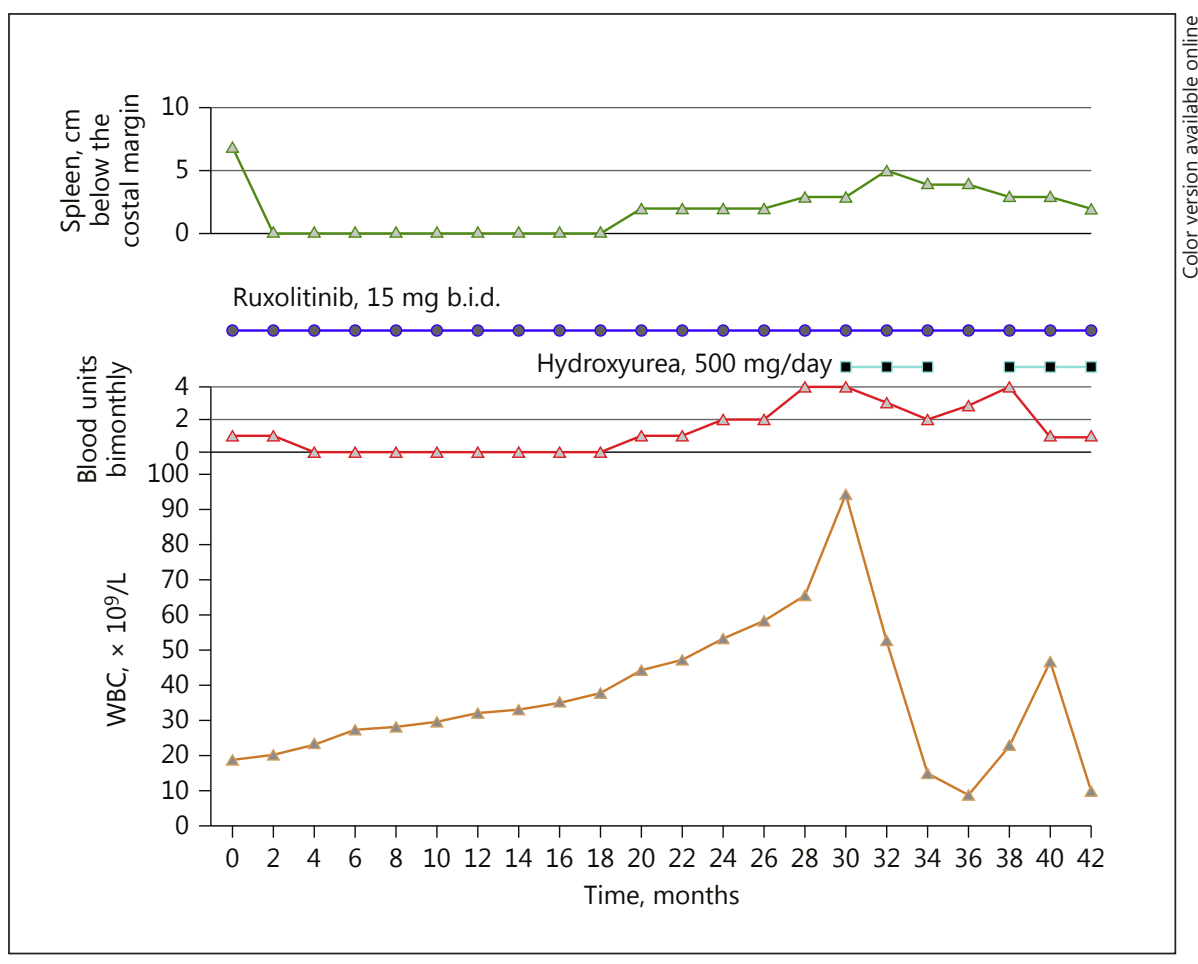

Fig. 1. White blood cell count (WBC), blood transfusion requirement, and spleen enlargement during ruxolitinib-hydroxyurea treatment.
Dr. Giovanni Caocci

Centro Trapianti di Midollo Osseo, Ospedale R. Binaghi

Via Is Guadazzonis 3

IT-09126 Cagliari (Italy)

E-Mail giovanni.caocci@unica.it 
months, the patient was stable and well. Thereafter, a myeloid-predominant leukocytosis progressively increased up to a white blood cell count (WBC) of $94.1 \times 10^{9} / \mathrm{L}$ in December 2016 , with $73.6 \times 10^{9} / \mathrm{L}$ neutrophils and $16.5 \times 10^{9} / \mathrm{L}$ monocytes. Bone marrow cytogenetics showed trisomy of chromosome 8 . The patient's symptoms reappeared, and recurrent pulmonary infections treated with antibiotics impaired her quality of life. In January 2017, treatment with HU $500 \mathrm{mg} /$ day was added to ruxolitinib. WBC dropped to normal values within 4 months, and thus HU was stopped. During the ruxolitinib-HU combination treatment, clinical condition and constitutional symptoms improved. No infections or side effects were recorded. Transfusion dependence did not increase. A second mild episode of leukocytosis $(\mathrm{WBC}=47.5$ $\times 10^{9} / \mathrm{L}$ ) occurred in August 2017 and was easily managed with a 3-month HU. Currently, the patient is doing well on $15 \mathrm{mg}$ b.i.d. ruxolitinib maintenance therapy with a palpable spleen of $3 \mathrm{~cm}$.

Myeloid leukocytosis represents a complication in $10-25 \%$ of MF patients $[5,6]$. So far, no role of ruxolitinib has been shown in leukocytosis. HU is a well-known cytoreductive drug. The combination therapy with both drugs has been rarely reported [7]. Cerchione et al. [3] described this association as being effective in controlling myeloproliferation and leukocytosis in a 57-year-old patient and reported an unexpected decrease in the need for blood trans- fusions. Polverelli et al. [8] reported on the efficacy of the same combination in the treatment of uncontrolled thrombocytosis in a 51-year-old man with MF following polycythemia vera. In vitro, the proapoptotic activity of ruxolitinib alone or in combination with $\mathrm{HU}$ was found to be similar [9]. Our case shows that the combination regimen has a good efficacy with regard to leukocytosis, with no increase in infective complications despite the potentially immunosuppressive role of ruxolitinib [10].

\section{Disclosure Statement}

The authors declare that there are no conflicts of interest to disclose.

\section{References}

1 Verstovsek S, Mesa RA, Gotlib J, Gupta V, DiPersio JF, Catalano JV, Deininger MW, Miller CB, Silver RT, Talpaz M, Winton EF, Harvey JH Jr, Arcasoy MO, Hexner EO, Lyons RM, Paquette R, Raza A, Jones M, Kornacki D, Sun $\mathrm{K}$, Kantarjian H: Long-term treatment with ruxolitinib for patients with myelofibrosis: 5 -year update from the randomized, doubleblind, placebo-controlled, phase $3 \mathrm{COM}$ FORT-I trial. J Hematol Oncol 2017;10:55.

-2 Kuykendall AT, Talati C, Al Ali N, Sweet K, Padron E, Sallman DA, Lancet JE, List AF, Zuckerman KS, Komrokji RS: The treatment landscape of myelofibrosis before and after ruxolitinib approval. Clin Lymphoma Myeloma Leuk 2017;17:e45-e53.

-3 Cerchione C, Peluso I, Nappi D, Pareto AE, Picardi M, Martinelli V, Pane F: Ruxolitinib rechallenge in combination with hydroxyurea is effective in reverting cachexia and reducing blood transfusion demand and splenomegaly symptoms in a patient with primary myelofibrosis. Ann Hematol 2017;96:697-699.
4 Cervantes F, Dupriez B, Pereira A, Passamonti F, Reilly JT, Morra E, Vannucchi AM, Mesa RA, Demory JL, Barosi G, Rumi E, Tefferi A: New prognostic scoring system for primary myelofibrosis based on a study of the International Working Group for Myelofibrosis Research and Treatment. Blood 2009;113:28952901.

5 Tefferi A, Lasho TL, Finke CM, Knudson RA Ketterling R, Hanson CH, Maffioli M, Caramazza D, Passamonti F, Pardanani A: CALR vs JAK2 vs MPL-mutated or triple-negative myelofibrosis: clinical, cytogenetic and molecular comparisons. Leukemia 2014;28: 1472-1477.

6 Yogarajah M, Tefferi A: Leukemic transformation in myeloproliferative neoplasms: a literature review on risk, characteristics, and outcome. Mayo Clin Proc 2017;92:11181128 .
7 Gangat N, Strand J, Li CY, Wu W, Pardanani A, Tefferi A: Leucocytosis in polycythaemia vera predicts both inferior survival and leukaemic transformation. Br J Haematol 2007; 138:354-358.

8 Polverelli N, Catani L, Vianelli N, Baccarani M, Cavo M, Palandri F: Ruxolitinib- but not fedratinib-induced extreme thrombocytosis: the combination therapy with hydroxyurea and ruxolitinib is effective in reducing platelet count and splenomegaly/constitutional symptoms. Ann Hematol 2015;94:15851587.

-9 Szymańska J, Smolewski P, Majchrzak A, Cebula-Obrzut B, Chojnowski K, Treliński J: Pro-apoptotic activity of ruxolitinib alone and in combination with hydroxyurea, busulphan, and PI3K/mTOR inhibitors in JAK2positive human cell line. Adv Clin Exp Med 2015;24:195-202.

10 Caocci G, Murgia F, Podda L, Solinas A, Atzeni S, La Nasa G: Reactivation of hepatitis B virus infection following ruxolitinib treatment in a patient with myelofibrosis. Leukemia 2014;28:225-227. 